\title{
HIJOS DE DESAPARECIDOS, ESPIRITUALIDAD NUEVA ERA Y LITERATURA DE AUTOAYUDA: ALEJANDRO CORCHS Y EL PERDÓN COMO GESTIÓN DE LA TRAGEDIA COLECTIVA
}

SONS OF DISAPPEARED, NEW AGE SPIRITUALITY AND SELF HELP LITERATURE: ALEJANDRO CORCHS AND FORGIVENESS AS MANAGEMENT OF THE COLLECTIVE TRAGEDY

FILS DE DISPARUS, SPIRITUALITE NOUVEL AGE ET LITTERATURE DE DEVELOPPEMENT PERSONNEL: ALEJANDRO CORCHS ET LE PARDON COMME PROCESSUS DE LA TRAGEDIE COLLECTIVE

FILHOS DE DESAPARECIDOS, ESPIRITUALIDADE NOVA ERA E LITERATURA DE AUTOAJUDA: ALEJANDRO CORCHS E O PERDÃO COMO GESTÃO DA TRAGÉDIA COLETIVA

Nicolás Viotti*

iD https://orcid.org/0000-0002-1868-5453

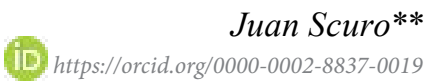

RESUMEN: Las víctimas de las últimas dictaduras en el cono sur generaron una gran cantidad de movimientos de reivindicación política, jurídica y humanitaria sobre el sufrimiento colectivo en base a argumentos de justicia, juicio y castigo. Aunque menos visibilizadas, existen también interpretaciones que presentan diferencias con las posiciones dominantes. En ese horizonte nos interesan las intervenciones del best-seller y líder espiritual uruguayo Alejandro Corchs, como ejemplo de respuesta organizada a la violencia política estatal en el código de la Nueva Era. Corchs ha desarrollado una reflexión biográfica y testimonial como hijo de desaparecidos de las dictaduras argentina y uruguaya, pero también como líder del movimiento espiritual Camino Rojo y escritor de auto-ayuda, centrado

\footnotetext{
* Doctor en Antropología Social; Investigador adjunto del Consejo Nacional de Investigaciones Científicas y Técnicas (CONICET) en el Instituto de Altos Estudios Sociales (IDAES) de la Universidad Nacional de San Martín (UNSAM), Buenos Aires, Argentina; e-mail: nicolas.viotti@gmail.com

** Doctor en Antropología Social; Profesor del Departamento de Antropología Social, Facultad de Humanidades y Ciencias de la Educación, Universidad de la República (UdelaR), Montevideo, Uruguay; e-mail: juanscuro@gmail.com
} 
en la idea de sanación de las heridas y la reconciliación. Este trabajo indaga en los escritos de Corchs sobre su experiencia personal como víctima directa, subrayando la idea del perdón como término clave.

Palabras clave: Alejandro Corchs; espiritualidad Nueva Era; literatura de autoayuda; memoria de la dictadura.

ABSTRACT: The victims of the last dictatorships in the southern cone generated movements of political, legal and humanitarian claim based on arguments of justice, human rights and punishment around the collective suffering. Although less visible, there are also interpretations that present differences with the dominant positions. In that horizon we are interested in the public discourse of the Uruguayan best-seller and spiritual leader Alejandro Corchs as an example of a New Age manner response to state political violence. Corchs has developed a biographical and testimonial reflection as a son of the disappeared of the Argentine and Uruguaian dictatorship, but also as a leader of Camino Rojo spiritual movement and self-help writer, focused on the idea of healing wounds and reconciliation. This article explores the writings of Corchs about his personal experience as a direct victim, underlining the idea of forgiveness as a key concept.

Keywords: Alejandro Corchs; New Age Spirituality; self-help literature; memory of the dictatorship.

RÉSUMÉ: Les victimes des dernières dictatures du Cône Sud ont donné lieu à l'organisation de nombreux mouvements de revendication politique, juridique et humanitaire basés sur la souffrance collective à partir des arguments de justice, jugement et châtiment. Bien que moins visibles, il existe également des interprétations qui présentent des différences avec les positions dominantes. Dans cet horizon, nous sommes intéressés dans les interventions d'Alejandro Corchs, célèbre leader spirituel uruguayen, ont été une réponse organisée qui a fait face à la violence politique exercée par l'Etat. Corchs a développé une réflexion biographique et testimoniale aigue en étant fils de disparus des dictatures uruguayenne et argentine, mais également en étant leader du mouvement spirituel Camino Rojo et figure de la littérature de développement personnel, dont l'idée centrale était la guérison des blessures et la voie à la réconciliation. Cet article analyse l'expérience personnelle de Corchs en tant que victime directe à partir de ses écrits. Il y est souligné que l'idée du pardon est un élément clé pour comprendre ses idées.

Mots-clés: Alejandro Corchs; spiritualité Nouvel Age; littérature de développement personnel; mémoire de la dictature. 
Hijos de desaparecidos, espiritualidad nueva era y literatura de autoayuda: Alejandro Corchs y el perdón como gestión de la tragedia colectiva

RESUMO: As vítimas das últimas ditaduras no cone sul geraram uma grande quantidade de movimentos de reivindicação política, jurídica e humanitária em base ao sofrimento coletivo sob argumentos de justiça, juizo y castigo. Embora menos visivel, também existem interpretações que apresentam diferenças com as posições dominantes. Nesse horizonte, estamos interessados nas intervenções do best-seller e líder espiritual uruguaio Alejandro Corchs, como um exemplo de resposta organizada à violência política estatal, no código da Nova Era. Corchs tem desenvolvido uma reflexão biográfica y um depoimento como filho de desaparecidos das ditaduras argentina e uruguaia, mas também como líder do movimento espiritual Camino Rojo y escritor de autoajuda, centrado na ideia de cura e reconciliação. Esse trabalho indaga nos escritos de Corchs e sua experiência pessoal como vítima direta, destacando a ideia de perdão como conceito chave.

Palavras-chave: Alejandro Corchs; espiritualidade Nova Era; literatura de autoajuda; memoria da ditadura.

\section{INTRODUCCIÓN}

Durante las últimas décadas los discursos y prácticas vinculados con la espiritualidad estilo Nueva Era han salido de los espacios alternativos o restringidos de los talleres, las terapias alternativas y los grupos religiosos heterodoxos. Este tipo de espiritualidad atraviesa ámbitos diversos y permea instituciones y nuevos modos de interacción social cotidiana, tensionando las imágenes nacionales clásicas, como por ejemplo el mentado monopolio del catolicismo en Argentina o el laicismo radical en Uruguay. Al mismo tiempo, la difusión de este tipo de prácticas reconfigura las fronteras entre lo religioso, lo espiritual y lo secular. En ese contexto, llama la atención como algunos discursos espirituales sirven como modos de gestión del sufrimiento movilizado por tragedias colectivas. Entre ellas, nos interesan aqui algunas formas de interpretación espiritual de la tragedia social, política y personal de las últimas dictaduras en Argentina y Uruguay.

En un pasaje del libro de autoayuda espiritual más vendido en Uruguay, pero también con repercusión en Argentina, puede leerse este pasaje que evoca a la madre desaparecida durante la dictadura 
en una vivencia de reconciliación y sanación provocada por plantas alucinógenas:

"Estaba dentro del cuerpo de mi madre, cuando estaba presa durante la dictadura. Si bien estaba adentro, sentía todas sus sensaciones, como un espectador. Pero las sentía y vivía muy intensamente. Empecé a llorar muy fuerte. Llegué a gritar de dolor, pero sin pánico. Gemía, con la sensación de que me estaba curando de algo" (Corchs, 2007, p. 180).

El protagonista de esa experiencia espiritual es Alejandro Corchs Lerena, hijo de Elena Lerena y Alberto Corchs, uruguayos desaparecidos en Argentina durante la dictadura militar en diciembre de 1977, cuando él tenía veintiún meses. Desde hace dos décadas es un renombrado escritor de best-sellers espirituales. Sus libros y sus intervenciones públicas en charlas, conferencias y entrevistas llamaron la atención de ambos lados del Rio de la Plata por combinar una trayectoria que rechaza el estatuto de "víctima" de la dictadura y que desarrolla un particular modo de entender el sufrimiento, en una clave personal y espiritual, provocado por la política de desaparición forzada de las dictaduras de Uruguay y Argentina.

La figura pública de Alejandro Corchs resulta interesante por varias razones. En ella se combinan diferentes trayectorias: la del hijo de desaparecidos, la del referente espiritual y la del escritor de literatura de desarrollo personal. Esta articulación condensa en un producto cultural específico, que excede el caso de Corchs, un modo en que tragedias colectivas o situaciones de sufrimiento colectivo son releídas y procesadas por concepciones holistas y sacralizadas del yo que contestan las ideas más convencionales de la "víctima" como parte de un fenómeno político-institucional y releen el sufrimiento como una oportunidad de transformación personal.

Este tipo de espiritualidad contemporánea supone un tipo de religiosidad que no se enmarca dentro de los límites convencionales de lo "religioso", asociado a una institución con un centro fijo, una jerarquía y un sistema coherente de preceptos públicamente descriptos en normas explícitas como las llamadas religiones eclesiales (Carozzi, 2000; Viotti, 2010). La llamada espiritualidad estilo Nueva Era ocupa espacios novedosos como los talleres de crecimiento personal, 
Hijos de desaparecidos, espiritualidad nueva era y literatura de autoayuda:

Alejandro Corchs y el perdón como gestión de la tragedia colectiva

la literatura de masas y las intervenciones mediáticas (Semán y Rizzo, 2013; Semán, 2003; De la Torre, Gutiérrez Zuñiga y Juárez Huet, 2013; Semán y Viotti, 2018). Asimismo, esta configuración espiritual cuenta con referentes que no son reclutados en los contextos habituales de formación de "especialistas religiosos", sino en trayectorias que articulan la psicología heterodoxa, la experimentación espiritual y la industria cultural (Semán y Battaglia, 2012). Estos aspectos, que poseen diversos canales de difusión y gran variedad de usos, hacen de la espiritualidad estilo Nueva Era un dispositivo con gran impacto social. Esa relevancia, sin embargo, no siempre ha sido suficientemente visibilizada por los estudios sociales de la religión, que han relegado su lugar y su importancia creciente en la cultura contemporánea a una zona "periférica" del campo religioso o a una "heterodoxia" por su carácter híbrido entre la religión y la psicología (Semán y Viotti, 2018). Por el contrario, en este trabajo queremos insistir en que su fuerza performativa tiene alcances significativos en la vida social contemporánea, modulando concepciones sobre el sufrimiento y sobre la tragedia de la última dictadura en una clave nueva.

El objetivo de este trabajo es, entonces, reconstruir la teoría nativa implícita en torno a la idea del "perdón" que Alejandro Corchs despliega, focalizando en sus lógica interna y los modos de mediación social que propone. El trabajo analiza el contenido de la obra de Corchs, pero también se detiene en sus intervenciones públicas en los medios masivos escritos y audiovisuales tanto de Argentina como de Uruguay. Al mismo tiempo muestra cómo una configuración emergente recompone la relación entre lo personal y lo colectivo, y pone en tensión las reivindicaciones más convencionales de "memoria, verdad y justicia" y la idea de "víctima", un aspecto abiertamente analizado por la literatura especializada dedicada a los movimiento sociales y los espacios de demanda pública en torno al terrorismo de Estado de la década de 1970 (Da Silva Catela, 2001; Jelin, 2018; Veccioli, 2013). Lejos de abonar la hipótesis de una despolitización o de una individualización radical asociada a la espiritualidad Nueva Era, el trabajo quiere subrayar que existe una politicidad que, entendida desde la lógica de las teorías nativas, produce un desplazamiento desde lo colectivo a una primacía de lo personal como eje del cam- 
bio. Un proceso que no deja de manifestar fuertes tensiones y controversias con los modos de reivindicación de justicia, victimización y de politicidad que han organizado la experiencia social reciente y la reflexión de las ciencias sociales sobre esos problemas.

\section{ALEJANDRO CORCHS: ENTRE LA ESPIRITUALIDAD NUEVA ERA Y LA LITERATURA DE MASAS}

El exilio hizo que Corchs naciera en Buenos Aires, en marzo de 1976, poco antes de que sus padres fueran secuestrados en esa misma ciudad, en diciembre de 1977. La tragedia colectiva, singularizada en su propia trayectoria vital, es el germen del futuro escritor y líder espiritual. Su trayectoria la va construyendo de a retazos, a medida que logra recordar, que obtiene información, y que le van contando todo lo sucedido. Al principio la narrativa de sus abuelos, luego la psicoterapia y la búsqueda de información en archivos y familiares. Más tarde, el camino espiritual centrado en las prácticas neochamánicas, un espacio de identificación que le permitió construir su historia primero, escribirla después y convertirse luego en un exitoso escritor y líder espiritual.

\subsection{La llegada al neochamanismo}

La historia que cuenta Corchs de su vida está repleta de momentos dramáticos, de vueltas del destino (o intervenciones del Gran Espíritu), de personajes misteriosos, de pérdidas y reencuentros. Todo esto hilvanado con sencilla pero conmovedora pluma en sus libros autobiográficos. Su estancia en Buenos Aires fue corta, y poco tiempo después de la desaparición de sus padres volvió a Uruguay donde fue creciendo apoyado por sus abuelos. La literatura esotérica fue llegando a su vida y junto a la psicoterapia fueron convirtiendo su vida en un misterio. De adolescente incrédulo, nocturno y arrogante fue pasando gradualmente a prestar mayor atención a lo "misterioso" que lo rodeaba. Esto, tal como él lo describe, ocurrió de la mano de personajes que fue encontrando, que le hacían notar su 
Hijos de desaparecidos, espiritualidad nueva era y literatura de autoayuda: Alejandro Corchs y el perdón como gestión de la tragedia colectiva

carácter de "elegido". Como por ejemplo el vidente que consultó, sugerido por su terapeuta, y que comenzó a describir sorpresivamente para él varios episodios de la vida del joven y de su carácter. Entre otras cosas, aquel vidente le explicó que era la décima persona de una lista de diez a las que el misterioso vidente debía ayudar a encontrar su misión personal, y le dijo: "Sos la única que me faltaba. Sos la décima persona. Vos vas a guiar a los jóvenes de América. No tenés una idea de la cantidad de jóvenes que te van a seguir" (Corchs, 2007, p. 97).

Las auspiciosas palabras del vidente se sumaban a otra sugerencia de su terapeuta, que le planteó que en vez de continuar el trabajo con ella sería mejor acercarse a caminos terapéutico-espirituales de trasfondo indígena, donde ceremonias como la "búsqueda de visión" podrían ayudarlo más que ella a trabajar aspectos de su niñez que el no lograba recordar. Sin saberlo, Corchs estaba cada vez más cerca del Camino Rojo y de convertirse en un líder importante de este grupo.

Lo que en nuestras latitudes se conoce como Camino Rojo responde principalmente al liderazgo de Aurelio Díaz Tekpankalli, creador del Fuego Sagrado de Itzachilatlan, una convergencia de elementos de la mexicanidad y de prácticas de nativos de Norteamérica que puede ser comprendido dentro de las redes de la neomexicanidad, un movimiento de fusión entre lo político y lo espiritual, de carácter panindigenista y de revalorización de modos ancestrales de vida (De la Torre y Gutiérrez Zúñiga, 2017). Tekpankalli reunió y adaptó diferentes rituales como la Danza del Sol, los Temazcal y la Búsqueda de Visión, creando una nueva institucionalidad para estas prácticas, que comenzó a difundir muy fuertemente por Sudamérica desde los inicios de la década de 1990.

En el Camino Rojo encontraría a su familia, su historia y su reconciliación. La llegada a este espacio espiritual también tuvo su cuota de misterio. Quien estaba comenzando a liderar ese grupo era el ex docente de la Universidad de la República, el psicólogo gestáltico Alejandro Spangenberg. El acercamiento de Corchs al Camino Rojo fue a través de Spangenberg, de quien su terapeuta le había facilitado el contacto. Llamarlo e intentar marcar un encuentro con él se convertiría en su primera prueba a superar. Tras varios llamados 
por parte de Corchs, solo recibía la negativa de parte de la secretaria de Spangenberg de que este pudiera recibirlo. Los intentos fueron varios hasta que Corchs se decidió a abandonar la idea. Entonces, cuenta Corchs, tras su desilusión por no conseguir el encuentro con Spangenberg recibe una llamada de Spangenberg que le dice: " $\mathrm{Pa}$ saste la primera prueba: darte cuenta de que podés vivir sin este camino" (Corchs, 2007, p.115). Con este tipo de "eventos singulares" Corchs construye una narración llena de momentos cargados de intensidad y misterio, de señales y pruebas a ser superadas en las que no existe lo casual, por el contrario todo parece estar entramado en un plan cósmico.

La narrativa pública de Corchs está cargada de acontecimientos de este tipo, adivinaciones y predicciones que construyen la trayectoria de un "elegido" que sólo debe darse cuenta de los misterios que lo rodean y asumir su lugar. Por ejemplo, este tipo de señales continuarían tras su primer encuentro, tan esperado, con Spangenberg. El psicólogo le explicó al novato que el mexicano Aurelio Díaz Tekpankali, fundador del Camino Rojo en México, le había dicho a Spangenberg que un día llegaría a él un joven a quien debería guiar. "Aurelio está ahora en México" le dijo Spangenber, y agregó: "Anoche se me presentó en un sueño. Me dijo que ese joven eras tú" (Corchs, 2007, p. 117).

El neochamanismo es, en muchos aspectos, un capítulo o un espacio más o menos delimitado dentro de las prácticas, lógicas y desarrollo de las espiritualidades de la Nueva Era. Ambos son hijos de procesos de búsqueda e incorporación de espiritualidades fuertemente vehiculizadas por los movimientos contraculturales, psicodélicos y de "expansión de la conciencia" que se produjeron principalmente en los Estados Unidos de la década de 1960 en adelante. En el marco de lo que posteriormente se identificó como espiritualidad Nueva Era, la fascinación por las culturas nativas del continente americano fueron un motor de búsqueda de saberes y prácticas específicas que acabarían dando forma al dispositivo del neochamanismo. Nada mejor que tradiciones "no modernas" al alcance de los investigadores y curiosos para alimentar la crítica contracultural a las lógicas modernas dominantes, incluyendo epistemologías, cosmologías y formas políticas alternativas. 
Hijos de desaparecidos, espiritualidad nueva era y literatura de autoayuda: Alejandro Corchs y el perdón como gestión de la tragedia colectiva

José Guilherme Magnani estudia el circuito neo-esotérico en San Pablo e identifica un conjunto de prácticas neochamánicas o de chamanismo urbano, llamando la atención sobre la especificidad del neochamanismo como un fenómeno cercano a la espiritualidad Nueva Era y distinguiéndolo del chamanismo "tradicional", con fuerte presencia en las sociedades indígenas de Brasil. Allí, según este autor, prevalecen la autonomía, el potencial individual y la posibilidad de que "todos pueden ser chamanes", aspectos netamente occidentales modernos e impensables en contextos indígenas (Magnani, 2005, p. 222). En Argentina y Uruguay el lugar de lo "indígena" está caracterizado por su invisibilización y ocupa un lugar simbólico diferencial en la narración pública de la nación. Por lo tanto, la incorporación de estas prácticas proviene de narraciones singulares que reinventan lo "indígena" en una clave diferente a la brasilera, mucho más distantes de la experiencia cotidiana de colectivos indígenas realmente existentes.

En Argentina, María Julia Carozzi muestra la gradual incorporación de estas prácticas al complejo alternativo en Buenos Aires por medio de psicólogos gestálticos o de inspiraciones alternativas a mediados de los 1990 (Carozzi, 2000), un proceso que ha sido analizado recientemente por Soledad del Rio (2018). A su vez, en Argentina también puede encontrarse el uso de sustancias alucinógenas en movimientos con un formato religioso más convencional, que se han establecido por medio de la transnacionalización de las denominadas "religiones ayahuasqueras brasileras" (Labate y Jungaberle, 2018) como el Santo Daime o la União do Vegetal. De modos similar, en Uruguay el escenario de las prácticas neochamánicas también se inicia a mediados de la década de 1990 con la llegada del Camino Rojo y de la iglesia del Santo Daime, que tienen al consumo ritual de ayahuasca como elemento central (Apud 2013, 2015a, 2015b; Apud y Scuro, 2015; Apud, Scuro y Petrone, 2013; Scuro 2012, 2013, 2016, 2018; Scuro, Giucci y Torterola, 2018).

En Uruguay, el psicólogo gestáltico Alejandro Spangenberg comenzó a interesarse por estas prácticas, realizando la serie de búsquedas de visión que están pensadas según el diseño de Tekpanka1li. Esto supone, entre otras cosas, una práctica muy específica que 
denominan "plantarse" que implica el ayuno solitario "debajo de un árbol" durante algunos días, acompañados por el uso de plantas alucinógenas. Esta práctica se realiza primero con una duración de cuatro días, luego por siete, después por nueve y finalmente por trece, en donde se cierra el ciclo de iniciación. Originalmente estas ceremonias eran lideradas por Tekpankalli en Uruguay pero pronto pasaría Spangenber a tomar un rol protagónico y de liderazgo. Las diferencias con Tekpankalli no demoraron en llegar y fueron siendo cada vez más notorias. Diferencias de estilo de conducción y liderazgo, las formas de relacionamiento y jerarquías y la fuerte impronta del mundo gestáltico que había en el grupo uruguayo llevaron a una ruptura con la institución transnacional liderada por Tekpankalli. La creciente familia del Camino Rojo en Uruguay, como se identifican, pasó a denominarse El Camino de los Hijos de la Tierra más recientemente. La impronta gestáltica y la figura de Spangenberg y su familia fueron aspectos determinantes en el rumbo del grupo en Uruguay. Cuando aun Tekpankalli visitaba Uruguay para conducir la "búsqueda de visión", llegó Alejandro Corchs al mundo del Camino Rojo. La primera práctica a la que concurrió Corchs, en la que se "plantó" por cuatro días, fue la misma en que Spangenberg completaba sus trece días. Spangenber presentó a Corchs a Tekpankalli, explicándole que Alejandro era el muchacho del que le había hablado. Ante esto, Tekpankallí saludó a Corchs diciéndole: "Bienvenido. Hace mucho tiempo que te estábamos esperando. Es un placer darle la mano al líder de los jóvenes" (Corchs, 2007, p. 139-140).

Así describe Corchs su iniciación y su vocación de líder espiritual dentro de un movimiento de búsqueda personal de sanación y de cambio de vida. Más adelante veremos cómo esa experiencia iniciática se enlaza con su biografía y se alimentan mutuamente, produciendo un personaje que hace de su vida personal un hecho colectivo, un testimonio de transformación. Al mismo tiempo, veremos cómo su obra y sus intervenciones públicas dan cuenta de una demanda social en torno a las lenguajes de la autoayuda y el mejoramiento personal, pero también resultan controvertidos frente a la reivindicación de "memoria, juicio y castigo" y el movimiento de derechos humanos como un todo. 
Hijos de desaparecidos, espiritualidad nueva era y literatura de autoayuda:

Alejandro Corchs y el perdón como gestión de la tragedia colectiva

\subsection{El autor de best-sellers}

En la última década comenzó a consolidarse fuertemente el campo de las espiritualidades neochamánicas en Uruguay y la popularidad de prácticas como la búsqueda de visión, los temazcales y las ceremonias de ayahuasca fueron aumentando. La amplia difusión acerca de los usos de la ayahuasca han hecho proliferar los espacios y settings en los cuales es posible tener experiencias de este tipo, participar en diferentes rituales y pasar a formar parte de grupos de tipo neochamánico. Al mismo tiempo, esas prácticas son acompañadas por modos de institucionalización de los códigos de la Nueva Era a través de espacios y mediadores no convencionales: la literatura de masas, los medios de comunicación y la industria cultural en general.

El período también coincide con la publicación y explosivas ventas de los libros de Corchs, además de su presencia en infinidad de medios de comunicación, presentaciones públicas, realización de talleres, charlas y cursos. Este crecimiento de su obra como autor de literatura de ayuda personal está, así mismo, en sintonía con la consolidación de un espacio específico vinculado con a la industria cultural y a los medios de masas como vehículo de difusión de este dispositivo espiritual que, como señalan Semán y Rizzo (2013), en las últimas décadas comienza a producir autores locales. Si bien incorporan algunos elementos difundidos por procesos de transnacionalización del código de la Nueva Era, presentan elaboraciones locales que recuperan aspectos nacionales específicos. En ese sentido, el boom editorial de Corchs puede compararse con otros fenómeno regionales como la consolidación de Paulo Coelho a nivel regional y global o en Argentina Claudio María Domínguez, difusores de una espiritualidad de masas que combinan contracultura, Nueva Era y catolicismo (Semán, 2003; Semán y Battaglia, 2012).

Con siete libros publicados, miles de ejemplares vendidos (incluyendo traducciones al inglés), viajes y presentaciones permanentes en varios países, Corchs es un joven líder seductor de un público que lo recibe emocionado por su propia historia y la forma en que ha ido elaborando su sufrimiento. Antes de la publicación de sus libros, participó de diferentes espacios sociales y políticos relacionados al 
tema de la desaparición de personas en la dictadura. Como hijo de desaparecidos ha integrado la organización "Madres y Familiares de Uruguayos Detenidos Desaparecidos", también ha participado de encuentros de la Comisión para la Paz, creada por el gobierno uruguayo en el año 2000, y otras instancias. Siempre se ha mantenido lejos de la militancia partidaria, que suele considerar un espacio nocivo. A pesar de su relativa lejanía de los espacios políticos tradicionales, su discurso y praxis no dejan de ser políticos, aunque en una nueva clave permeada de una estética y retórica de la Nueva Era. Su énfasis en la sanación a través del "amor" y el "perdón" son aspectos resonantes en los espacios Nueva Era pero claramente disonantes en ámbitos políticos y sociales más convencionales.

Siendo un gran conocedor de los medios de comunicación por haber trabajado en ese entorno en su juventud y teniendo una gran historia para contar que toca núcleos sensibles muy delicados de la historia reciente en nuestros países, Alejandro Corchs y el Camino Rojo se fueron retroalimentando en un gradual proceso de legitimidad y visibilización pública.

Sin duda Corchs es un ejemplo de los modos en que se procesa localmente un fenómeno más amplio vinculado con la literatura de autoayuda y la espiritualidad neochamánica en el Rio de la Plata. El boom de Alejandro Corchs como escritor de autoayuda en Uruguay, y más tímidamente en Argentina, tiene múltiples factores que tienen que ver con procesos de diversificación de la literatura espiritual, de un nuevo modo de presencia de temáticas religiosas-espirituales en los medios de masas y en la industria cultural, en nuevas formas de mediación social religiosa que no siguen el modelo de la iglesia y el ideario jerarquizado de las instituciones religiosas más convencionales (Semán y Viotti, 2018; De la Torre, Gutiérrez Zúñiga y Juárez Huet, 2013).

De lo que no cabe duda es de la gran popularidad y aceptación del mensaje de Corchs. Además de ser un líder espiritual, neochamán y "hombre medicina", se ha convertido en un exitoso escritor de best-sellers. En ese contexto nos preguntamos: ¿Cuál es el lugar del perdón en la teoría nativa del dispositivo que emerge alrededor de Alejandro Corchs? ¿Cómo se vincula ese proceso con 
Hijos de desaparecidos, espiritualidad nueva era y literatura de autoayuda:

Alejandro Corchs y el perdón como gestión de la tragedia colectiva

las formas contemporáneas de gestionar una tragedia colectiva como la de las últimas dictaduras en Argentina y Uruguay? ¿Cómo se desplazan el lugar de la figura de la "víctima" a una subjetividad activa, responsable del propio bienestar?

\section{EL PERDÓN COMO CÓDIGO DE TRANSFORMACIÓN}

La obra de Alejandro Corchs recorre temas vinculados al dolor, el perdón y la importancia de la cura como camino de vida. Sus temas rondan temáticas clásicas de la literatura de auto-ayuda y la espiritualidad: el trabajo con uno mismo, el reencuentro con los otros, el equilibrio, la "desvictimización” y la experiencia biográfica como legitimadora de un discurso y una práctica de cambio, la lucha contra el conflicto y la necesidad de la transformación de uno mismo.

Su primeros tres libros están organizados como una saga denominada El regreso de los hijos de la tierra, que funciona como una biografía personal pero también como un arquetipo de dilemas morales, experiencias de aprendizaje y lecciones de vida para sus lectores y lectoras. El camino del puma (2007) es el primer libro de Corchs, allí desarrolla por primera vez su reflexión autobiográfica, aunque la biografía y la experiencia personal son un recurso constante de sus libros y sus intervenciones públicas. Allí se pone de manifiesto de modo paradigmático la relación entre búsqueda personal, sanación y su experiencia como hijo de desaparecidos de las dictaduras uruguaya y argentina. La unión de la familia (2013a) y Viaje al corazón (2013b) continúan esa saga, volviendo eventualmente sobre su condición de hijo de desaparecidos en clave personal. La obra posterior de Corchs, que se despliega en títulos como Trece preguntas al amor, El camino a la libertad, Yo me perdoné e Inspiración ha desarrollado otros temas del gran abanico de la literatura de crecimiento personal y espiritualidad sobre las emociones, el amor y una vocación de "despertar la conciencia".

La problemática del "perdón" es un tema recurrente, que adquiere un sentido específico en su interpretación. El perdón es para Corchs un modo de aceptación de uno mismo y del estado de cosas del entorno, como camino de bienestar. El lugar paradigmático don- 
de este modelo de perdón se va a consolidar es en la propia tragedia personal del secuestro y desaparición de sus padres.

\subsection{Perdonarse: un camino personal}

El camino del Puma desarrolla una particular teoría del perdón. El relato sobre su vida en clave biográfica describe el secuestro sorpresivo de sus padres en Buenos Aires, su desaparición, cómo fue protegido por un vecino cuando todavía era un bebé y luego restituido a sus abuelos que lo criaron en Montevideo. También se detiene en su vida adolescente y otras desventuras personales de su juvenud durante la década de 1990 en Uruguay y un proceso de acercamiento a algunas prácticas de desarrollo personal, intereses esotéricos y la psicología transpersonal.

A partir de una serie de experiencias donde Corchs relata cómo entró en contacto con sus padres asesinados, experiencias que incluyen el juego de la ouija, la meditación profunda y la consulta con maestros espirituales, narra un episodio transformador en donde entra en contacto con las "emociones de su madre" durante su cautiverio. Según Corchs sus pensamientos y emociones "pasaban a través" en una conexión espiritual favorecida por una planta de poder y el contacto con el Gran Espíritu. Prácticas que conforman el circuito ritual del movimiento Camino Rojo y que son narradas como parte de un camino de descubrimiento de uno mismo y de "sanación de las heridas" personales.

Uno de los pensamientos y emociones de su madre, relata, mostraba la inquietud en momentos previos a su muerte sobre el destino de su hijo:

“Qué hicimos? Dejamos a Alejandro, lo perdimos. ¿Dónde estará ahora? ¿Estará vivo? ¿Muerto? ¿Lo habrán capturado? Y luego, esa voz que lo atraviesa continúa: "Pobre Ale que lo dejamos solo. Con todo lo que lo amamos. Con todo lo que lo amo. Ale, perdonanos que no pensamos que todo podía terminar así. Somos unos inconscientes. Perdonanos. Te amo mucho" (Corchs, 2007, p. 180).

La escena describe un profundo llanto, gritos y una sensación de estar en presencia de una situación de tortura donde él estaba 
Hijos de desaparecidos, espiritualidad nueva era y literatura de autoayuda: Alejandro Corchs y el perdón como gestión de la tragedia colectiva

oyendo lo que su madre oía. Al mismo tiempo, describe la presencia de un "espíritu protector" que lo cuidaba y de tener una sensación de "estar curando algo". Luego de esa situación de estar en presencia de su madre, Corchs describe otra experiencia en donde se desplaza hacia el interior de su padre durante su prisión y la sensación presente de sus pensamientos, su dolor y la preocupación por su hijo. En ese momento, percibió hasta qué punto nunca había entendido a sus padres, a los que les tenía rencor y culpaba por haberlo abandonado y no haberlo cuidado. Esa experiencia le permitió ponerse en el lugar de sus padres y, con la ayuda de ese espíritu protector, reconoció el amor que ellos sentían por él. El espíritu le indicó que en ese cuadrado donde estaba solo, durante el viaje inducido por la "medicina", sus padres y sus abuelos ya fallecidos estaban con él y lo abrazaban.

Luego de esa experiencia iniciática con la "medicina", Corchs recibió un llamado a transformarse y a trasformar al mundo. Algunos años antes un maestro le había dicho que era un espíritu muy viejo, uno de los más viejos que había conocido y que iba a transformar a los jóvenes. En esta última experiencia reafirmó esa misión de vivir el resto de su vida desde el amor y al servicio de los otros. Fue en ese momento que Tekpankalli, líder del Camino Rojo que guiaba la experiencia, luego de señalarle que había sido una "búsqueda caliente" le indicó: "Tu verdadera misión es llevar al espiritu, conectar al pueblo y llevarles el mensaje del amor" (Corchs, 2007, p.185).

La idea del perdón como un trabajo con uno mismo da cuenta de una concepción fuertemente autónoma de la subjetividad, un rasgo que está en sincronía con muchas de las descripciones del aspecto “interior" de la espiritualidad Nueva Era (Carozzi, 2000, 2004; ver también Frigerio, 2013). Sobre esa misma premisa se monta la centralidad de la experiencia personal como espacio de legitimidad. No es un conocimiento teórico o moralmente abstracto, sino la propia biografía y la experiencia personal de sufrimiento la que vehiculiza un saber legítimo. En este caso resulta significativo que esa experiencia personal se trenza con un proceso de tragedia colectiva, usualmente leído en una clave de derechos humanos y de víctimas del genocidio, que en el caso de Corchs es reinterpretado en clave personal como un elemento iniciático, como un camino de cambio y 
de cura en un horizonte espiritual. El perdón no es aquí un problema de relación con otros, no son otros, los victimarios, quienes tienen que ser perdonados. El sufrimiento es el punto de partida de un camino de perdón sobre uno mismo.

Como señala por ejemplo Illouz (2010), los saberes psicológicos en sus usos masivos se articulan con elementos espirituales y la autoayuda en una configuración emocional de trabajo con uno mismo como un lenguaje y una práctica que permite gestionar situaciones conflictivas. En ese sentido, la idea y la práctica del perdón puede leerse aquí no solo como una idea abstracta, sino como un modelo de acción ritual mediado por al experiencia extática de la "búsqueda de la visión" y la iniciación de un "camino espiritual" de transformación del yo que tiene una vocación misionera y expansiva que se beneficia de estrategias y recursos de la cultura de masas.

\subsection{El perdón en los medios}

Hay un momento muy relevante en la carrera de Corchs y su presencia en los medios masivos de comunicación. Este proceso de construcción y comunicación de sus ideas y vivencias en torno a la idea del perdón que estamos analizando aquí, tuvo un punto fuerte durante su debut como autor de masas. En la época de la presentación de El Camino del Puma, sus dichos acerca del perdón fueron explícitos en relación a temáticas complejas y sensibles para la vida política de Argentina y Uruguay. Las formas tradicionales de lucha por verdad y justicia que provienen de las organizaciones de víctimas del terrorismo de Estado y madres y familiares de detenidos desaparecidos, parecen estar lejos de abrazar ideas cercanas al concepto de perdón. Lejos de esto, suelen reivindicarse consignas tales como "ni olvido ni perdón" o "juicio y castigo".

En ese contexto la temática del perdón adquirió un lugar particularmente significativo y tuvo eco mucho más allá de su círculo específico como El Camino Rojo o sus lectores asiduos u ocasionales. Su mensaje se consolidó en espacios mucho más amplios por medio de un efecto en el periodismo especializado. Sobre todo en las secciones "calidad de vida" o "espiritualidad" de revistas de cir- 
Hijos de desaparecidos, espiritualidad nueva era y literatura de autoayuda: Alejandro Corchs y el perdón como gestión de la tragedia colectiva

culación masiva argentinas y uruguayas y su aparición en una gran cantidad de programas de radio y televisión.

En una nota publicada en la Revista femenina Ohlalá de Argentina, dedicada a la calidad de vida, el aconsejamiento personal en temas de desarrollo personal, se reivindica a Yo me perdoné y la obra de Corchs como un aporte a la calidad de vida y a la espiritualidad contemporánea que la revista difunde. "Alejandro supo transmutar su dolor en sabiduría e iniciar así su búsqueda espiritual" sostiene la autora (Alemano, 2016). A medio camino entre la espiritualidad y la psicología positiva, la presencia de Corchs en medios masivos o especializados en el mundo espiritual y las terapias alternativas va de la mano de un desplazamiento de la cultura de masas y la industria cultural a esas temáticas en la última década, ampliando el espectro de difusión del ideario y la sensibilidad Nueva Era en contextos que tradicionalmente se remitían a un psicoanálisis popular (Viotti, 2018).

En una entrevista realizada por un colectivo de crecimiento personal y espiritualidad llamado Semillas solares, Alejandro Corchs describe detenidamente su idea del perdón y cómo impactó en su biografía y en su actividad contemporánea como "hombre medicina". En esa oportunidad señalaba que:

"La puerta de la libertad viene con el perdón. Solo que el perdón no es hacia otros, sino hacia uno mismo. Siempre me preguntan acá y en Argentina como había hecho para perdonar a los militares que asesinaron a mis padres, y yo les decía no, yo me perdoné. Yo no puedo culpar a alguien que nunca culpé, y tampoco lo puedo perdonar. Lo que sí puedo es perdonarme a mí. Hubo un momento en mi vida, alrededor de los 18 o 19 años, en que me di cuenta que habia vivido suficiente dolor y que me merecía vivir otra vida que fuera sin ese dolor. Y que querer seguir buscando culpables en la discusión con los militares o con el gobierno era estar en el mismo lugar y que yo tenía que salir a buscar mi verdad porque aca no estaba y sí en un camino espiritual. Entonces en ese momento me perdoné, y justamente hoy siento el perdón como la clave, lo imprescindible para el camino espiritual." (Corchs, 2012)

A continuación se refiere a la idea de "justicia" y a la de "venganza" como un problema que aleja a las personas de asumir 
su propio sufrimiento como un momento que debe superarse por el reconocimiento el merecimiento personal del bienestar. El camino del conocimiento espiritual es, en última instancia, el camino del reconocimiento de que uno es merecedor del bienestar:

"Lo veo también trabajando como hombre medicina, viendo en la cantidad de almas de personas que fallecen y que no logran encontrar la luz para sus vidas porque simplemente no creen que la merecen y no lo pueden ir a tomar, creen que no son lo suficientemente puros o están todavía bañados en el resentimiento esperando una venganza o una justicia, entre comillas, (...) ellos mismos no creen que son la luz." (Corchs, 2012)

En otra aparición mediática significativa, la performance de Alejandro Corchs resume esta problemática. Entrevistado por Facundo Ponce de León en su ciclo de televisión uruguayo llamado Vidas durante 2009, Corchs desarrolló para un público amplio su trayectoria y sus posiciones. Corchs y Ponce de León se encuentran en un ambiente de naturaleza, la puesta de sol da paso a la noche y en torno a un fuego comparten mate y conversan. Entre los relatos de las experiencias de Corchs el conductor del programa le plantea al entrevistado una hipótesis en la cual sucede que ante un ritual del Camino Rojo se acerca uno de los militares que torturó a sus padres o que violó a su madre y le pide participar del mismo. Ponce de León le pregunta a Corchs si en esa situación aceptaría esta participación. Corchs, inmediatamente responde que con mucha alegría lo haría y luego agrega:

"Porque en realidad ayudándolos a sanarse también me sano yo. Yo creo que el perdón está concedido para todos y en realidad solo tienen que decidir tomarlo. No es algo que me tengan que pedir perdón a mí, primero se tienen que pedir perdón a ellos mismos. Ojalá lo pudieran hacer." (Corchs, 2009)

Esto coloca a Corchs en un lugar muy diferente en el espectro de discursos y prácticas provenientes de algunas organizaciones sociales que reclaman justicia y ciertos ámbitos políticos y militares donde prevalecen las nociones de confrontación o la "teoría de los dos demonios". Pero esta relocalización de su discurso en clave espiritual no necesariamente es cómplice o condescendiente de los hechos del pasado, como sí podrían ser interpretados algunos hechos políticos 
Hijos de desaparecidos, espiritualidad nueva era y literatura de autoayuda: Alejandro Corchs y el perdón como gestión de la tragedia colectiva

claves del llamado "cambio en paz" con el que se ha autodenominado el gobierno de la transición democrática a la salida de la última dictadura en Uruguay o la idea de "reconciliación" en Argentina.

Sin complicidad, pero también sin sed de venganza, el discurso de Corchs se articula en un nuevo espacio que de algún modo "expone" o "evidencia" actos en una retórica de evolución espiritual o de oportunidades individuales para alcanzar la "libertad" que borran los limites del conflicto entre víctimas y victimarios, pero al mismo tiempo dejan en segundo plano el reclamo de justicia y responsabilidad estatal. $\mathrm{Al}$ asumir que "ayudándolos a sanarse también me sano yo" o que "primero se tienen que pedir perdón a ellos mismos" se corre sutilmente del lugar de víctima para colocarlos a "ellos" en ese lugar. Él, que "ya se perdonó" ya salió de ese lugar y por eso puede "ayudarlos a sanarse" a "ellos", víctimas de su propia falta de amor, libertad y perdón en sus vidas, es un ejemplo viviente de un camino a seguir.

El perdón se despliega así como un leguaje y un código de transformación que "sana" el conflicto, que incluye a todas las partes, las que causan el sufrimiento y las que son afectadas por él. Este movimiento, en el que Corchs legitima su propio discurso y práctica poniendo en primera persona a su propio dolor, supone una subjetividad que no termina en uno mismo, sino que se expande en vínculos y conexiones, que incluye a antepasados y a "enemigos", conformando una imagen ideal de la vida social como armónica y en equilibrio.

\section{CONCLUSIONES}

Enlazando expresiones del neochamanismo contemporéno y lógicas locales inherentes a la historia reciente de Argentina y Uruguay, el fenómeno Corchs resulta un nodo de procesos complementarios. Por un lado es singificativo de un proceo de cambio religioso que incorpora discursos y prácticas que potencian la idea del cambio personal en base a experiencias sagradas de exploración de uno mismo. Por otro, de un modo de expansión de ese horizonte espiritual que no puede entenderse bajo la lógica de la religión instituida en base a un modelo eclesial clásico, sino a un modo de presencia en la vida social que remite a prácticas cotidianas, talleres y lecturas 
variadas así como a la circulación en la cultura de masas, los medios de comunicación y la industria cultural.

En términos estrictamente locales Corchs es una novedad significativa ya que se presenta como disruptivo de varios lugares comunes sobre el espacio religioso y político. En primer lugar, Corchs no solo presenta públicamente sus creencias y modalidad espiritual, sino que lo hace con éxito y de forma masiva. Este hecho evidencia una transformación en los modos de aparición pública de la espiritualidad estilo Nueva Era en el horizonte más amplio de la diversidad socio-religiosa contemporánea, donde parece posible expresar creencias y modalidades religiosas alternativas libremente, sin censura, persecución o condena. Un hecho que no debería hacernos olvidar que se trata de un hombre, blanco, heterosexual, de edad media y con un fuerte capital social y simbólico. El segundo aspecto en el que la performance de Corchs es disruptiva tiene relación con su forma de elaborar su condición de hijo de desaparecidos, produciendo un discurso claramente diferencial al de las organizaciones y proclamas dominantes sobre la militancia política y la represión estatal de la década de 1970. Y este es el punto neurálgico que hemos querido presentar en este trabajo. La retórica y praxis de esta sensibilidad espiritual para entender la tragedia de la desaparición de personas de las últimas dictaduras es distante de la hegemónica en los ámbitos políticos tradicionales. Imbuida de los temas de la sacralización estilo Nueva Era, la performance de Corchs no deja de apuntar a espacios semánticos de la memoria colectiva en fuerte disputa, pero desplazándola hacia una lógica encantada, en donde el perdón y la sanación recorren el sufrimiento colectivo.

Su particular trayectoria biográfica como hijo de desaparecidos de las dictaduras uruguaya y argentina no es un elemento anecdótico, sino la piedra de toque de una narración pública que hace del sufrimiento el fundamanto de un dispositivo de transfromación personal y de legitimidad de su liderazgo. En este sentido el caso de Corchs puede ser visto como un modo particular y sintomático en que los códigos de la espiritualidad Nueva Era leen la tragedia colectiva en clave de experiencia personal trágica: desplazando el lugar de la "víctima" y potenciando el lugar de la creatividad personal 
Hijos de desaparecidos, espiritualidad nueva era y literatura de autoayuda: Alejandro Corchs y el perdón como gestión de la tragedia colectiva

como vehículo de aprendizaje frente a la adversidad. Pero al imsmo tiempo, un código de construcción de una autoridad pública en base a valores emergentes en nuetras sociedades como los que tienen que ver con la autonomía personal, el bienestar y la armonía.

En ese movimiento se despliega una particular teoría del perdón en relación con el asesinato político de sus padres, que articula la biografía personal con una teoría más amplia sobre el bienestar personal en clave de cura espiritual que posee una vocación mucho más amplia como mensaje de transformación colectiva. Contra la imagen convencional y crítica de que la espiritualidad Nueva Era es un fenómeno alejado de la experiencia común y únicamente centrado en la experiencia personal o subjetiva, el caso de Corchs da cuenta de un particular despliegue entre lo íntimo y lo público que parecería presentar una idea del cambio en clave personal como fundamento de una transformación más amplia.

\section{REFERENCIAS}

ALEMANO, C. Hombre sensible: Alejandro Corchs, escritor y tanatólogo. Revista Ohlalá, Agosto, p.97, 2016.

APUD, I. El indio fantasmal es reclutado en la ciudad. Neochamanismo, sus orígenes y su llegada a Uruguay. Cuadernos de Antropología Social, 38:57-83, 2013.

APUD, I. Ayahuasca from Peru to Uruguay: Ritual Design and Redesign through a Distributed Cognition Approach. Anthropology of Consciousness, 26 (1): 1-27, 2015a.

APUD, I. Ayahuasca, Contexto Ceremonial y Sujeto. Análisis del Set and Setting a Partir de un Grupo Uruguayo de Terapias Alternativas. Journal of Transpersonal Research, 7 (1): 7-18, $2015 \mathrm{~b}$.

APUD, I; SCURO, J; PETRONE, V. Las tradiciones de la ayahuasca: su eco mediático y social en el Uruguay. Anuario de Antropología Social y Cultural en Uruguay, 11:55-69, 2013.

APUD, I; SCURO, J. Aportes para un debate sobre la regulación de la ayahuasca en el Uruguay. Anuario de Antropología Social y Cultural en Uruguay, 13:35-49, 2015.

CAROZZI, M. J. Ready to move along. The Sacralization of Disembedding 
in the New Age Movement and the Alternative Circuit in Buenos Aires. Civilisations, 51, p. 139-154, 2004.

CAROZZI, M. J. Nueva Era y terapias alternativas. Buenos Aires: EDUCA, 2000.

CORCHS, A. Yo me perdoné. Montevideo: Editorial Purificación - Memoria Viva, 2016.

CORCHS, A. La unión de la familia. El regreso de los hijos de la tierra. Montevideo: Ediciones Cruz del Sur, 2013a.

CORCHS, A. Viaje al corazón. El regreso de los hijos de la tierra. Montevideo: Ediciones Cruz del Sur, 2013b.

CORCHS, A. Entrevista realizada por el colectivo Semillas solares. Disponible en: https://semillassolares.com/entrevistas-semillassolares, 2012.

CORCHS, A. Entrevista realizada por Ponce de León para el programa Vidas. Disponible en: https://www.youtube.com/watch?v=rXrtGg5467U, 2009.

CORCHS, A. El camino del puma. El regreso de los hijos de la tierra. Montevideo: Ediciones Cruz del Sur, 2007.

DA SILVA CATELA, L. No habrá flores en la tumba del pasado. La Plata: Al Margen, 2001.

DE LA TORRE, R; GUTIÉRREZ ZÚÑIGA, C. Mismos pasos y nuevos caminos. Transnacionalización de la danza conchero azteca. México: El Colegio de Jalisco/ CIESAS, 2017.

DE LA TORRE, R; GUTIÉRREZ ZÚÑIGA, C; JUÁREZ HUET, N. (eds.). Variaciones y apropiaciones latinoamericanas del new age. México DF: CIESAS, 2013.

DEL RIO, M. S. Psicologización de la espiritualidad: cruces entre psicología, vegetalismo amazónico y antropología en un centro comunitario y terapéutico de la ciudad de Buenos Aires. Ciencias Sociales y Religión, 28, p. 158-171, 2018.

FRIGERIO, A. La ¿nueva? Espiritualidad: ontología, epistemología y sociología de un concepto controvertido. Ciencias Sociales y Religión, 24, p. 209-231, 2016.

FRIGERIO, A. Lógicas y límites de la apropiación new age: donde se detiene el sincretismo. In: DE LA TORRE, R; GUTIÉRREZ ZÚÑIGA, C; JUÁREZ HUET, N. (eds.). Variaciones y apropiaciones latinoamericanas del new age. México DF: CIESAS, p. 47-70, 2013. 
Hijos de desaparecidos, espiritualidad nueva era y literatura de autoayuda:

Alejandro Corchs y el perdón como gestión de la tragedia colectiva

ILLOUZ, E. La salvación del alma moderna. Terapia, emociones y cultura de la auto-ayuda. Buenos Aires: Katz, 2010.

JELIN, E. La lucha por el pasado. Buenos Aires: Siglo XXI, 2018.

Labate, B. \& Jungaberle, H. The internationalization of ayahuasca. Berlin: Lit-Verlag, 2011.

MAGNANI, J. G. C. Xamãs na cidade. Revista USP, 67, p. 218-227, 2005.

SCURO, J. Sair para buscar, encontrar e voltar: de como surgiu uma igreja do Santo Daime no Uruguai. Debates do NER, 13(21):151-180, 2012.

SCURO, J. A formação do campo ayahuasqueiro uruguaio, meios de comunicação e subjetividades. In: Gomes P, Fausto Neto A, Sbardelotto M, Magalhães de Souza T (Orgs.). Midias e religiões: a comunicação e a fé em sociedades em midiatização.: São Leopoldo: Unisinos-Leiria, 2013.

SCURO J. Circuitos transnacionais da ayahuasca: efeitos no Uruguai. In: Tavares, F; Giumbelli, E. (Orgs). Religiões e temas de pesquisa contemporâneos: diálogos antropológicos. EDUFBA, Salvador, 2016.

SCURO, J. Interpellations and Chellenges in the Neoshamanic and Ayahuasca Fields in Uruguay. In: Labate B, Cavnar C (Orgs). The Expanding World Ayahuasca Diaspora. Appropriation Integration and Legislation. Routledge. Londres y Nueva York, 2018.

SCURO, J., GIUCCI, G; TORTEROLA, S. Camino Rojo from Mexico to Uruguay. Spiritual leaderships, trajectories and memory. International Journal of Latin American Religions, 2(2), 248-271, 2018.

SEMAN, P. Notas sobre Pulsação entre Pentecostes e Babel. O caso de Paulo Coelho e seus leitores. In: O. Velho (org), Circuitos infinitos. Comparações e religiões no Brasil, Argentina, Portugal França e Grã-Bretanha. San Pablo: Attar/CNPq, p. 127-157, 2003.

SEMÁN, P; BATTAGLIA, A. Nuevas formas y caminos para el sacerdocio. Civitas, 12, p. 439-452, 2012.

SEMÁN, P; RIZO, V. Tramando religión y best sellers. La literatura masiva y la transformación de las prácticas religiosas. Alteridades, 23, p. 79-92, 2013.

SEMAN, P; VIOTTI, N. New Age spiritualty in Argentina. Cultural change and epistemological challenge. Journal of Latin American Religions, 3 (1), 2019. 
VECCIOLI, V. Las víctimas del terrrorismo de Estado y la gestión del pasado reciente en Argentina. Papeles del CEIC, 90, 2013.

VIOTTI, N. Psicología positiva y cultura de masas. Una mirada descentrada sobre los saberes del "yo" en la Revista Ohlalá. In: J. Caravaca, D. Claudia y M. Plotkin (eds), Saberes desbordados. Historias de diálogos entre conocimientos científicos y sentido común (Argentina, siglos XIXY XX). Buenos Aires: Libros del IDES, 2018.

VIOTTI, N. El lugar de la creencia y la transformación religiosa en las clases medias de Buenos Aires. Apuntes de Investigación del CECyP, 18, pp. 39-68, 2010. 